\title{
Functional and Anatomical Features of the Dorsal Column Nuclei in Mammals and Lower Animals
}

\author{
Sami I. Zaqout ${ }^{1, *}$, Saleh M. Al-Hussain ${ }^{2}$ \\ ${ }^{1}$ Anatomy Department, Faculty of Medicine, Islamic University of Gaza, Gaza, Palestine \\ ${ }^{2}$ Anatomy Department, Faculty of Medicine, Jordan University of Science and Technology, Irbid, Jordan \\ *Corresponding author: sizaqout@iugaza.edu.ps \\ Received January 10, 2013; Revised February 03, 2013; Accepted February 15, 2013
}

\begin{abstract}
The dorsal fasciculi of the spinal cord are known as the chief pathways for the conduction of impulses underlying deep sensibility and tactile discrimination from limbs which reach the thalamus and ultimately the cerebral cortex after a relay at a bulbar level, the dorsal column nuclei. It is believed that the development of the dorsal fasciculi and their nuclei in the mammalian and primate series is correlated with increasing sensory discrimination in the skin and the increased development of proprioceptive sense in the limb musculature. In this review we will discuss the reflection of the development of limbs and sensory discrimination in lower animals and mammals on the organization and some functional aspects of these nuclei.
\end{abstract}

Keywords: Gracile, Cuneate, Neurons, Development

\section{Introduction}

The dorsal column nuclei (DCN) are interested part of the central nervous system for studying the somatosensory pathways [1]. These nuclei receive primary afferent fibers from the trunk and limbs and give rise to the medial lemniscus that ascends upward and terminate in the thalamus. The fibers then reach the primary somatosensory area in the cerebral cortex. It is commonly known that the term DCN refers to the gracile nucleus $(\mathrm{Gr})$ and cuneate nucleus $(\mathrm{Cu})$. Actually, the tailed-animals often possess an accessory cell group called nucleus of Bischoff (Bi) situated in the median plane between the two gracile nuclei of each side and is considered as a part of DCN [2,3]. The external cuneate nucleus and nucleus $\mathrm{Z}$ (a rostrolateral extension of $\mathrm{Gr}$ ) are sometimes considered as a DCN [4,5], but they will be out of the focus of this review.

\section{First Appearance of the DCN}

The rostral extension of the dorsal fasciculi of the spinal cord is studied in different vertebrate species. The first appearance of the DCN have been found in reptiles [6]. Some authors denied the presence of the DCN and medial lemniscus system in subreptilian vertebrates [6,7]. Others suggested that a primordial DCN are present in the obex region (the junction between the open medulla and closed medulla) of amphibians $[8,9,10]$.

\section{Amphibians}

The first vertebrates known to have developed sensory fibers projecting to supraspinal levels are the amphibians
[11,12]. Loosely packed neurons are collected at the rostral end of the dorsal spinal column in the frog medulla extending from the second spinal root to the obex [10] (Figure 1). Although not divided into $\mathrm{Gr}$ and $\mathrm{Cu}$, this neuronal collection would appear as a homologue of the DCN in mammals [13]. Three different neuronal populations have been described based on the size of the nerve soma [10]. The most frequent neurons (>70\%) were medium-sized, measured $10-20 \mu \mathrm{m}$ in diameter, and were homogeneously distributed throughout the nucleus. Neurons which were less than $10 \mu \mathrm{m}$ in diameter comprised $15 \%$ of the nucleus and were more frequent in the rostral portions. Neurons which were over $20 \mu \mathrm{m}$ in diameter represented the remainder and were more prominent in the caudal parts of the nucleus.

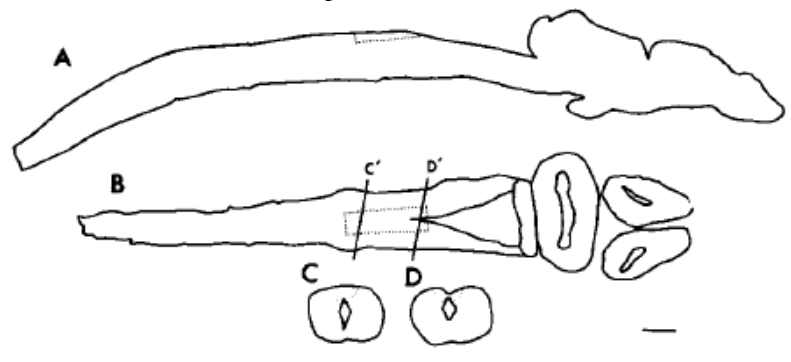

Figure 1. The approximate location of the dorsal column nucleus in the frog brain. Figure from Silvey et al. [10].

\section{Reptiles}

Reptiles showed the first definite appearance of the DCN with $\mathrm{Gr}$ and $\mathrm{Cu}$ subdivisions [6]. The appearance of these nuclei in reptiles might be associated with the development of limbs which is necessary for the terrestrial life. These nuclei have been found in limbed lizards [14,15,16,17], iguana [18], turtle [19] and alligator 
[6,20,21]. However, the snakes, which do not have limbs, have also DCN [6,11,19,22,23,24].

The DCN in some tailed-reptiles was divided into large lateral part, considered as the main DCN, and small medial part, referred as the $\mathrm{Bi}$ in either side of the midline (e.g., Tegu lizard [15], garter snake [22] and Python $[19,23,24]$ ) (Figure. 2). However, Bi is not described in other tailed-reptiles such as some types of lizards [16], turtles [19] and boas [11].

The DCN of the Python reticulates, the world's longest snake and longest reptile, has been studied ultrastructurally [25]. On the basis of the size of the nerve somata, nuclear morphology and cytoplasmic organelles features, three neuronal types have been described in both the main $\mathrm{DCN}$ and the $\mathrm{Bi}$.

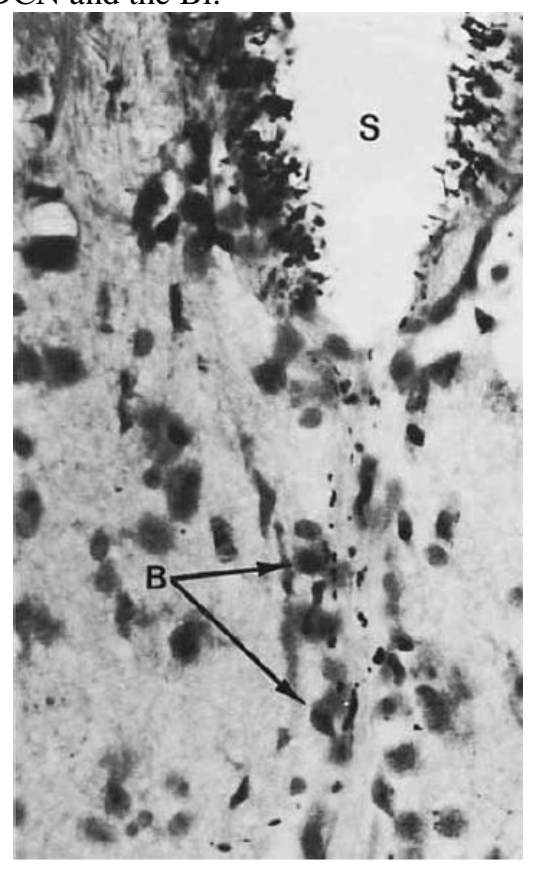

Figure 2. Bischoff nucleus the (B) in snake. Figure from Jacobs and Sis [22].

\section{Birds}

The dorsal column system of birds is of a primitive type presumably due in part to the lack of discriminative sensibility of skin covered with feathers. In pigeon for instance, the DCN are not well developed as are in mammals, but somehow separable into two components [26] (Figure 3) with broad outline resembling some mammalian projections [27]. No classification of the DCN neurons in any bird species has been reported in literature.

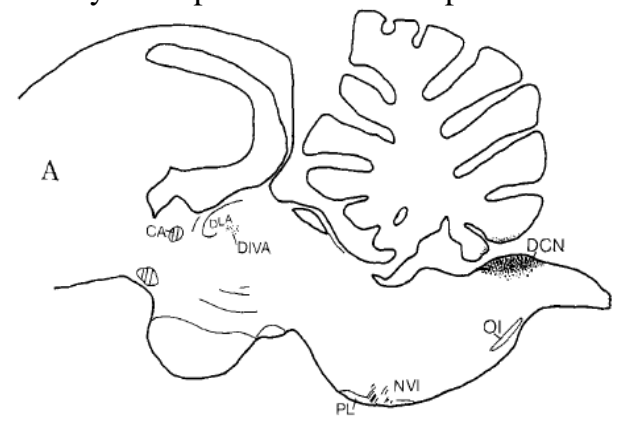

Figure 3. The approximate location of the DCN in the pigeon brain. Figure from Wild [26].

\section{Sea Mammals}

Sea mammals, whose mode of life places no premium on a detailed knowledge of the surrounding objects and who lack prehensile and manipulative ability, have a poorly developed dorsal-column system [28].

\section{Mammals}

It is believed that the development of the dorsal fasciculi and their nuclei in the mammalian and primate series is correlated with increasing sensory discrimination in the skin and the increased development of proprioceptive sense in the limb musculature [28]. The DCN can be divided clearly into $\mathrm{Cu}$, which receives afferents from the forelimb (upper limb) [29] and Gr, which receives afferents the hindlimb (lower limb) [30]. A third nucleus known as $\mathrm{Bi}$, is present between the gracile nuclei of both sides in some tailed-mammals such as raccoon [31] and opossum [32]. The $\mathrm{Bi}$ in tailed-mammals resembles those described in some tailed-reptiles and receives afferents from the tail $[2,6]$. As the case in some tailed-reptiles, $\mathrm{Bi}$ is not described in other mammalian species with well-developed tails such as the spider monkey [28], the rat $[33,34,35]$ and the cat $[30,36,37]$.

Golgi and/or Nissl studies of the DCN in rat $[33,38]$, cat, [29,30,36,39] monkey [40] and camel [41,42] showed that it contain a heterogeneous neuronal population of various shapes and somata diameters $(7 \mu \mathrm{m}-74 \mu \mathrm{m})$. Using horseradish peroxidase (HRP) injection into ventropostero-lateral nucleus in the cat thalamus, gracilothalamic projection neurons identified as large cells ( $\geq 18 \mu \mathrm{m}$ in diameter) confined to a region known as the "cell nest region" $[43,44]$. Based on their retrograde response to upper mesencephalon lesions in the cat, the DCN neurons projecting into the medial lemniscus were identified as large round cells located at the dorsal part of the cell nest region [36].

Anatomical studies showed that a series of collaterals immerge from dorsal column afferents into several rostrocaudal levels of the $\mathrm{Cu}$ and $\mathrm{Gr}$ [37]. These collaterals might be related with the multiple representation of receptive areas. However, the neuronal connections of afferent, efferent, and intranuclear fibers may vary greatly at different rostrocaudal levels [36]. Based on anatomical and physiological studies in several mammalian species such as monkey [45] and cat $[27,46,47]$, the DCN have been divided into three regions: caudal, middle and rostral.

\subsection{Rats}

In the rat, The Gr lies close to the midline at the dorsal surface of the medulla oblongata extending from $\mathrm{C} 1$ level of the spinal cord to $300 \mu$ rostral to the obex [33] (Figure 4). Cytoarchitecturally, the Gr zones are less well defined than those in cat and monkey (described on 7.2 and 7.3). Nissl-stained preparations confirmed the presence of two distinct regions [33]. The first region extends from C1 level of the spinal cord to $200-300 \mu$ caudal to the obex and is characterized by a heterogeneous neuronal population with diameters ranging from 8 to $24 \mu$. The second region extends more rostrally and its neurons show fewer large neurons $(>18 \mu)$. Golgi-stained preparations 
showed that caudal part of the Gr contains neurons with vertically oriented dendrites known as the "dendritic column"; while the rostral part contains various neuronal types with transversely or vertically oriented dendrites [33].

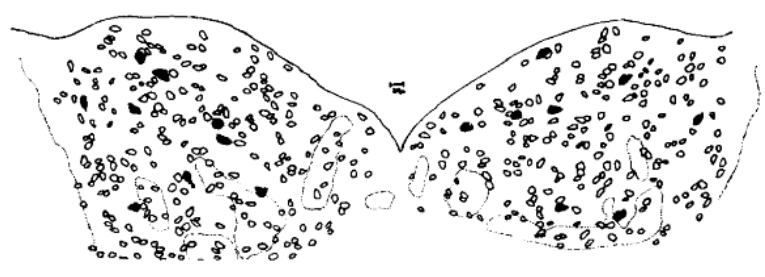

Figure 4. Camera lucida drawing of a transverse section from adult rat brain stained with cresyl violet demonstrating the area occupied by $\mathrm{Gr}$ at the level $250 \mu$ caudal to the obex. Figure from Gulley [33].

An early study of the rat $\mathrm{Cu}$ using Nissl and Golgi staining methods revealed no rostrocaudal divisions [35]. In other later Nissl study, however, the preparations showed that the rat $\mathrm{Cu}$ is separable into two rostrocaudal regions [38] as the case in the rat Gr. Moreover, studies of primary afferent projections to the rat $\mathrm{Cu}$ [48] found a region located caudal to the obex expected to be functionally homologue to the middle region in cats and the pars rotunda in primates (described on 7.2 and 7.3) [49]. Other studies using HRP, histochemistry and immunohistochemistry techniques also confirmed the presence of a middle region in the rat $\mathrm{Cu}[48,50,51,52]$ in spite of its unclear identification using Nissl and Golgi staining methods.

\subsection{Cats}

Based on the Nissl preparations of the Gr of the cat, the longitudinal axis of the nucleus is divided into three distinct regions [30] (Figure 5): (1) the "reticular region" rostrally is characterized by small scattered neurons, (2) the "cell nest region" in the middle region contained clusters of larger round neurons, (3) the "caudal region" contained much larger neurons. The afferent fibers carrying vibration, hair stimulation and foot pad stimulation are somatotopically arranged and terminated mainly by synapsing with the neurons of the middle region "cell nest region" [30,31,36,53]. The neurons of the cell nest region have restricted receptive fields, small cortical input and, most of them, project to the medial lemniscus [30,31]. There are also neurons which are responsive to hair stimulation, light pressure and touch located at the rostral region "reticular region" of the $\mathrm{Gr}$ $[30,31,53]$. The neurons of this region are loosely organized homogeneous triangular or fusiform cells $[36,37,39,54]$. Comparing with the neurons of the cell nest region, the receptive fields of the hair stimulation in the reticular region are larger, the dorsal column input to this region is lesser and not arranged somatotopically, the neurons of this region have large cortical input and a small proportion of its neurons contribute to the medial lemniscus fibers [30]. The physiological studies of the $\mathrm{Gr}$ in the cat showed also that the terminal ends of the nerve fibers which carry the sensation from the distal parts of the hindlimb "the foot" have more extensive representation at the $\mathrm{Gr}$ and are a located dorsomedial to those of the nerve fibers which carry the sensation from the proximal parts of the hinlimb $[21,55]$.

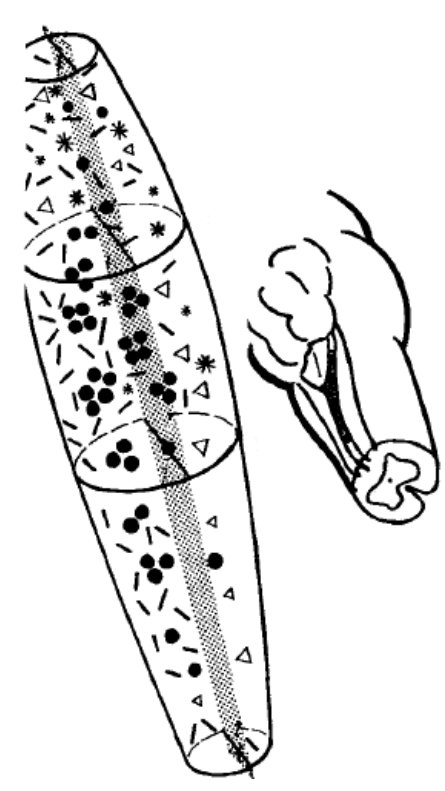

Figure 5. Heterogeneity of Gr of the cat. Figure from Berkley [43].

\subsection{Monkeys}

The location and distribution of the DCN in rhesus monkey have been studied [59] (Figure 6). The physiological studies of the $\mathrm{Cu}$ in galagos [56] and New and Old World monkeys [57,58,59,60,61,62,63] showed that the cell clusters in the main part of the nucleus (pars rotunda) is related to specific inputs from the hand. These cell clusters, identified as cytochrome oxidase (CO)patches, receive inputs from digits $1-5$ in a lateromedial sequence. The major portions of both the $\mathrm{Cu}$ and $\mathrm{Gr}$ in the primates are well differentiated into ovals $\mathrm{CO}$-patches reflecting cell clusters. The arrangement of these $\mathrm{CO}$ patches in the $\mathrm{Gr}$ is less regular in arrangement and more spread out along the rostrocaudal length of the nucleus. The differentiation of these nuclei in other mammals is often less pronounced [64].

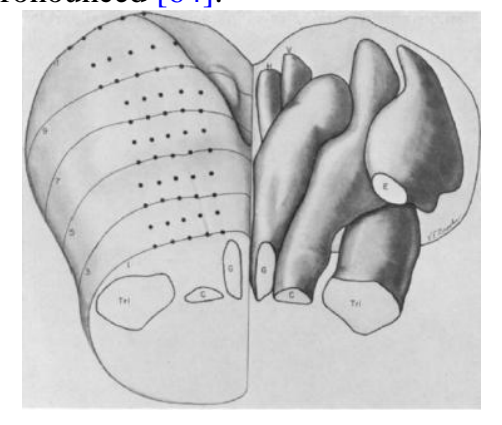

Figure 6. DCN in rhesus monkey. Figure from Biedenbach [40].

The $\mathrm{Cu}$ of the Macaca fascicularis has been studied ultra-structurally [65]. The neurons somata were varied in shape and size with short axes ranged from 4 to $22 \mu \mathrm{m}$ and long axes ranged from 9 to $37 \mu \mathrm{m}$. The neurons were classified into three groups according to their nuclear morphology, the arrangement of the rough endoplasmic reticulum (RER) and the appearance of the Golgi complexes.

\subsection{Camels}

The camel is one of the largest animals on earth. It has adapted to live in desert in several ways. It has long, 
strong legs. Powerful muscles in the upper part of the legs allow the animal to carry heavy loads for long distances. The large size and heavy duties of the camel may create need to develop sophisticated balance system including well developed DCN (Figure 7). Recent Golgi studies on the camel $\mathrm{Gr}$ [41] and $\mathrm{Cu}$ [42] revealed the presence of a wide variety of neurons comprising a broad spectrum of sizes, shapes, dendritic density, dendritic branching pattern, somatic spines and appendages and dendritic spines and appendages. These studies demonstrated certain complex morphological features of neurons in the camel DCN such as wide variation of somatic and dendritic spines and appendages, flower-like dendritic ends, spiny axons and profusely branched axons. Most of these neuronal characterizations are not described in the previous studied species. This may reflect a part of relationship between the special characteristic camel's limbs and the diversity of the DCN neurons.

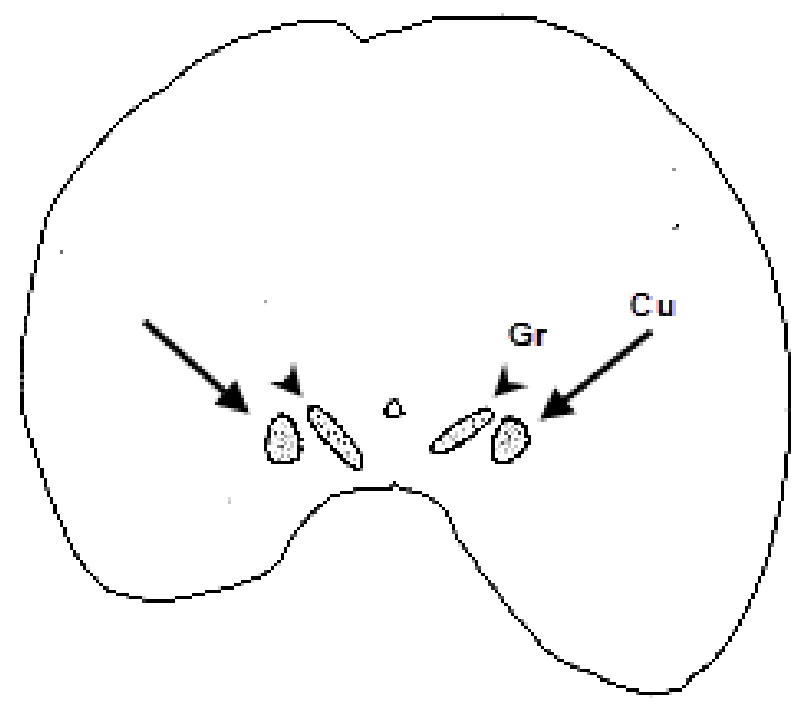

Figure 7. Camera lucida drawing of a transverse section from adult camel brain stained with H\&E demonstrating the area occupied by Gr at the level of $200 \mu$ caudal to the obex.

\section{Conclusion}

The first vertebrates known to have developed sensory fibers projecting to supraspinal levels are the amphibians. However, reptiles showed the first definite appearance of the $\mathrm{DCN}$ with $\mathrm{Gr}$ and $\mathrm{Cu}$ subdivisions. A third nucleus known as $\mathrm{Bi}$, is present between the gracile nuclei of both sides in some tailed-reptiles and -mammals. Based on anatomical and physiological studies in several mammalian species, the DCN have been divided into three regions: caudal, middle and rostral. Several neuronal types have been described in the DCN of mammals and lower animals. Neurons in the DCN of the camel seem to have the most complex features among the species studied so far by Golgi impregnation. It seems that the complexity of neurons in these nuclei is correlated with increasing the importance of sensations such as discriminative touch in the skin and proprioception (sense of position and sense of movements) in the muscles and joints. This review may shed a light on the subdivisions of these nuclei and the importance for further physiological and molecular studies to reveal their specific functional rules.

\section{References}

[1] Bermejo, P.E., Jimenez, C.E., Torres, C.V. and Avendano, C., "Quantitative Stereological Evaluation of the Gracile and Cuneate Nuclei and Their Projection Neurons in the Rat," J. Comp. Neurol., 463. 419-433. 2003.

[2] Bischoff, E., "Zur Anatomie der Hinterstrangkerne bei Saugethieren," Jb. Psychiat. Neurol., 18. 371-384. 1899.

[3] FCAT_Federative Committee on Anatomical Terminology 1998.

[4] Brodal, A. and Pompeiano, "The vestibular nuclei in the cat," $J$. Anat., 91. 438-454. 1975.

[5] Tracey, DJ. and Waite, P.M.E., Somatosensory system: The rat nervous system, Academic Press, In: Paxinos G. (ed.) San Diego, 1995, 689-704.

[6] Ariens-Kappers, C.U., Huber, G.C. and Crosby, E.C., The Comparative Anatomy of the Nervous System of Vertebrates, Including Man, New York Macmillan. 1936.

[7] Hayle, T.H., "A comparative study of spinal projections to the brain (except cerebellum) in three classes of poikilothermic vertebrates," J. Comp. Neurol., 149. 463-467. 1973.

[8] Crockett, D.R., Foschini, D.R., Girgis, W.S. and Egger, M.D., "Immunocytochemical localization of the low-affinity nerve growth factor receptor (p75NGFR) in the cuneate nucleus of the rat and its relationship to cytochrome-oxidase activity," Brain Res., 603. 324-327. 1993

[9] Corvaja, N., Pellegrini, M. and Buisseret-Delmas, C., "Ultrastructure of supraspinal dorsal root projections in the toads. I. The obex region," Brain Res., 142. 413-424. 1978.

[10] Silvey, G.E., Gulley, R.L. and Danvidoff, R.A., "The frog dorsal column nucleus," Brain Res., 73. 421-437. 1974.

[11] Ebbesson, S.O.E., "Brain stem afferents from the spinal cord in a sample of reptilian and amphibian species," Ann. N.Y. Acad. Sci., 167. 80-102. 1969.

[12] Hursh, J.B., "Relayed impulses in ascending branches of dorsal root fibers," J. Neurophysiol., 3. 166-174. 1940.

[13] Szabo, T., "Existence de fibres longues d'origine ganglionnaire dans les colonnes posterieures dela moelle de Grenouille," Arch. Sci. physiol., 9. 27-33. 1955.

[14] Ebbesson, S.O.E., "Ascending fibre projections from the spinal cord in the tegu lizard (Tupinambis nigre punctatus)," Anat. Rec., 154. 341-342. 1966.

[15] Ebbesson, S.O.E., "Ascending axon degeneration following hemisection of the spinal cord in the tegu lizard (Tupinambis nigropunctatus)," Brain Res., 5. 178-206. 1967.

[16] Goldby, F. and Robinson, L.R., "The central connections of the dorsal spinal nerve roots and the ascending tracts in the spinal cord of Lacerta uiridis," J. Anat. (Lond.), 96. 153-170. 1962.

[17] Jacobs, V.L., "A spinovestibular component of the dorsal funiculus in a lizard (Lacerta virids)," Anat. Rec., 157. 264-265. 1967.

[18] Joseph, B.S. and Whitlock, D.C., "Central projections of brachial to lumbar dorsal roots in reptiles," J. Comp. Neurol., 132. 469-484. 1968.

[19] Kusuma, A. and ten Donkelaar, H.J., "Dorsal root projections in various types of reptilian,” Brain Behav. Evol., 17. 291-309. 1980.

[20] Huber, G.C. and Crosby, E.C., "On thalamic and tectal nuclei and fibre paths in the brain of the American alligator," J. Comp. Neurol., 40. 97-227. 1926.

[21] Kruger, L., Siminoff, R. and Witkovsky, P., "Single neuron analysis of dorsal column nuclei and spinal nucleus of trigeminal in cat," J. Neurophysiol., 24. 333-349. 1961.

[22] Jacobs, V.L. and Sis, R.F., "Ascending projections of the dorsal column in a garter snake (Thamnophis siritails): A degeneration study," Anat. Rec., 196. 37-50. 1980.

[23] Molenaar, G., "The rhombencephalon of Python reticulatus, a snake possessing infrared receptors," Neth. J. Zool., 27. 133-180. 1977.

[24] ten Donkelaar, H.J. and Nieuwenhuys, R., The Brainstem.: Biology of the Reptilia, New York Academic Press In: Gans C (ed.), 1979, 133-200.

[25] Tan, C.K. and Gopalakrishnakone, P., "The fine structure of the dorsal column nucleus and the nucleus of bischoff of the python (Python reticulatus)," J. Morpho., 190. 243-257. 1986.

[26] Wild, J.M., "The avian somatosensory system. I. Primary spinal afferent input to the spinal cord and brainstem in the pigeon (Columba liuia)," J. Comp. Neurol., 240. 377-395. 1985. 
[27] Berkley, K.J., Budell, R.J., Blomqvist, A. and Bull, M., “Output Systems of the Dorsal Column Nuclei in the Cat," Brain Res. Revi., 2. 199-225. 1986.

[28] Chang, H.T. and Ruch, T.C., "Organization of the dorsal columns of the spinal cord and their nuclei in the spider monkey," J. Anat. 81. 140-149. 1947.

[29] Keller, J.H. and Hand, P.J., "Dorsal root projections to nucleus cuneatus of the cat," Brain Res., 20. 1-17. 1970.

[30] Hand, P.J., "Lumbosacral dorsal root terminations in the nucleus gracilis of the cat. Some observations on terminal degeneration in other medullary sensory nuclei," J. Comp. Neurol., 1261. 137-156. 1966.

[31] Johnson, J.I., Welker, W.I. and Puaols, B.H., "Somatotopic organization of racoon dorsal column nuclei," J. Comp. Neurol., 132. 1-44. 1968.

[32] Hamilton, T.C. and Johnson, J.I., "Somatotopic organization related to nuclear morphology in the cuneate-gracile complex of opossums Didelphis marsupialis virginiana," Brain Res., 51. 125140. 1973.

[33] Gulley, R.L., "Golgi studies of the nucleus gracilis in the rat," Anat. Rec., 177. 325-442. 1973

[34] Tan, C.K. and Wong, W.C., "The Structure and Connections of the Dorsal Column Nuclei," In: Harrisonmand RJ, Navaratnam V (eds.): Progress in Anatomy, Cambridge University Press 2. 161177. 1982.

[35] Valverde, F., "The pyramidal tract in rodents. A study of its relations with the posterior column nuclei, dorsolateral reticular formation of the medulla oblongata and cervical spinal cord," $Z$. Zellforsch., 71. 297-363. 1966.

[36] Kuypers, H.G.J.M. and Tuerk, J.D., "The distribution of the cortical fibers within the nuclei cuneatus and gracilis in the cat," $J$. Anat., 98. 143-162. 1964.

[37] Ramo'n, y Cajal S., "Hictologi'e du Syste'me Nerveux de l'Homme et des Vertbres," A. Mjoine, Paris 1. 889-911. 1909.

[38] Basbaum. A.I. and Hand, R.J., "Projections of cervicothoracic dorsal roots to the cuneate nucleus of the rat, with observations on cellular "bricks"', J. Comp. Neurol., 148. 347-360. 1973.

[39] Taber, E., "The cytoarchitecture of the brain stem of the cat. I. Brain stem nuclei of cat,"J. Comp. Neurol., 116. 27-70. 1961.

[40] Biedenbach, M.A., "Cell density and regional distribution of cell types in the cuneate nucleus of the rhesus monkey," Brain Res., 45. 1-14. 1972.

[41] Al-hussain, S.M., Al-saffar, R.A. and Zaqout, S.I., "Morphological and quantitative study of neurons in the gracile nucleus of the camel brain stem," J. Behav. Brain Sci., 2. 35-47. 2012.

[42] Zaqout, S.I., Al-hussain, S.M., Al-saffar, R.A. and El-dwairi, Q.A., "A Golgi Study of the Camel Cuneate Nucleus," Anat. Rec., 295. 2191-2204. 2012.

[43] Berkley, K.J., "Different targets of different neurons in nucleus gracilis of the cat," J. Comp. Neurol., 163. 285-303. 1975.

[44] Blomqvist, A. and Westman, J., "Combined HRP and FinkHeimer staining applied on the gracile nucleus in the cat," Brain Res., 99. 339-342. 1975.

[45] Boivie, J., "Anatomical observations on the dorsal column nuclei, their thalamic projection and the cytoarchitecture of some somatosensory thalamic nuclei in the monkey," J. Comp. Neurol., 178. 17-48. 1978.

[46] Ellis, J.L.C. and Rustioni, A., "A correlative HRE Golgi, and EM study of the intrinsic organization of the feline dorsal column nuclei," J. Comp. Neurol., 197. 341-367. 1981.

[47] Nyberg, G. and Blomqvist, A., "The central projection of muscle afferent fibers to the lower medulla and upper spinal cord: an anatomical study in the cat with the transganglionic transport method," J. Comp. Neurol., 230. 99-109. 1984.
[48] Maslany, S., Crockett, D.P. and Egger, M.D., "Somatotopic organization of the dorsal column nuclei in the rat: transganglionic labelling with B-HRP and WGA-HRP," Brain Res., 564. 56-65. 1991.

[49] Maslany, S., Crockett, D.R., Egger, M.D., "The cuneate nucleus in the rat does have an anatomically distinct middle region," Neuros. Let., 139. 130-134. 1992.

[50] Crockett, D.R., Zhang, J. and Egger, M.D., "A modified cytochrome oxidase staining procedure reveals "patches" of intense metabolic activity in the cuneate nucleus of the adult rat," Anal. Rec., 226. 23A. 1990a.

[51] Crockett, D.R., Harris, S.L., Maslany, S., Zhang, J. and Egger, M.D., "Anatomical investigations of afferents to the cervical internal basilar nucleus in the rat: Anterograde, intra-axonal and immunocytochemical labelling studies," Soc. Neurosci. Abstr., 16. 221. $1990 \mathrm{~b}$.

[52] Crockett, D.R., Harris, S.L., Maslany, S., Egger, M.D. "Calcitonin gene-related peptide (CGRP) immunoreactive fibers are primarily restricted to a "middle" region of the cuneate nucleus in the rat," Soc. Neurosci. Abstr., 17. 289. 1991.

[53] Gordon, G. and Jukes, M.G.M., "Dual organization of the exteroceptive components of the cat's gracile nucleus," J. Physiol. (Lond.), 173. 263-290. 1964.

[54] Taber, E., "Histogenesis of brain stem neurons studied autoradiographically with thymidine $-\mathrm{H}^{3}$ in the mouse," Anat. Rec., 145. 291. 1963.

[55] Ueyama, T., Houtani, T., Ikeda, M., Sato, K., Sugimoto, T. and Mizuno, N., "Distribution of primary afferent fibers projecting from hindlimb cutaneous nerves to the medulla oblongata in the cat and rat," J. Comp. Neurol., 341. 145-158. 1994.

[56] Strata, F., Coq, J.O., Kaas, J.H., "The chemo- and somatotopic architecture of the galago cuneate and gracile nuclei," Neuroscience, 116. 831-850. 2003.

[57] Florence, S.L., Wall, J.T. and Kaas, J.H., "Somatotopic organization of inputs from the hand to the spinal gray and cuneate nucleus of monkeys with observations on the cuneate nucleus of humans," J. Comp. Neurol., 286. 48-70. 1989.

[58] Florence, S.L., Wall, J.T. and Kaas, J.H., "Central projections from the skin of the hand in squirrel monkeys," J. Comp. Neurol., 311. 563-578. 1991.

[59] Noriega, A.L. and Wall, J.T., "Parcellated organization in the trigeminal and dorsal column nuclei of primates," Brain Res., 565. 188-194. 1991.

[60] Wu, C.W. and Kaas, J.H., "The effects of long-standing limb loss on anatomical reorganization of the somatosensory afferents in the brainstem and spinal cord," Somatosens. Mot. Res., 19. 153-163. 2002.

[61] Xu, J. and Wall, J.T., "Cutaneous representations of the hand and other body parts in the cuneate nucleus of a primate, and some relationships to previously described cortical representations," Somatosens. Mot. Res., 13.187-197. 1996.

[62] Xu, J. and Wall, J.T., "Functional organization of tactile inputs from the hand in the cuneate nucleus and its relationship to organization in the somatosensory cortex," J. Comp. Neurol., 411. 369-389. 1999a.

[63] $\mathrm{Xu}, \mathrm{J}$. and Wall, J.T., "Evidence for brainstem and suprabrainstem contributions to rapid cortical plasticity in adult monkeys," J. Neurosci., 19. 7578-7590. 1999b.

[64] Qi, H.X. and Kaas, J.H., "Organization of Primary Afferent Projections to the Gracile Nucleus of the Dorsal Column System of Primates," J. Comp. Neurol., 499. 183-217. 2006.

[65] Wen, C.Y., Wong, W.C. and Tan, C.K., "The fine structural organization of the cuneate nucleus in the monkey (Macaca fascicularis)," J. Anat., 127. 169-180. 1978. 